\title{
Distribution, fine-scale subdivision, and population size of San Joaquin kit foxes in the Ciervo-Panoche Natural Area, California
}

\author{
Tammy R. Wilbert ${ }^{1,2}$ (1) $\cdot$ Deborah A. Smith Woollett ${ }^{3} \cdot$ Michael F. Westphal $^{4} \cdot$ Alice Whitelaw $^{3} \cdot$ Katherine Ralls $^{1}$. \\ Jesús E. Maldonado'
}

Received: 9 July 2018 / Accepted: 8 November 2018 / Published online: 11 February 2019

(c) The Author(s) 2019

\begin{abstract}
The endangered San Joaquin kit fox (SJKF; Vulpes macrotis mutica) is strongly linked ecologically to xeric areas with high abundance of kangaroo rats. Endemic to the San Joaquin Desert of central California, the elusive nature of SJKF, coupled with steady habitat loss and lack of comprehensive surveys, has precluded efforts to quantify the species' population size and distribution, especially in the central and northern parts of its range. Because the Ciervo-Panoche Natural Area contains the largest area of high-quality habitat in this central/northern region, we conducted systematic transect surveys for SJKF scats with professionally trained dog-handler teams throughout the area during 2009-2011. We collected almost 600 scats over $473 \mathrm{~km}$ of transects, documenting the freshness and location of each scat. Using molecular methods, we identified 93 SJKF individuals ( 56 males and 37 females) from 332 samples. Half of the individuals carried a mtDNA haplotype with a 16 bp deletion that had not been previously detected in other areas surveyed. Four individuals were recaptured in 2010 and five in 2011, including one female that was captured every year. We documented a unique mtDNA haplotype and more individuals across a wider area of the Ciervo-Panoche Natural Area than expected. Population analyses revealed two distinct subpopulations, with low connectivity between foxes in the Panoche Valley that are separated by hills with unsuitable habitat from those on the adjacent valley floor next to a major Interstate highway (I-5). While individuals detected within $6 \mathrm{~km}$ of each other were closely related, overall relatedness within each subpopulation approached zero. Genetic population models indicated a conservative population estimate of 90 kit foxes in total, with 60-90 individuals in the Panoche Valley and 17-27 individuals in the I-5 area. These results will help to inform management of the SJKF and identify areas that may be important to maintaining connectivity between populations.
\end{abstract}

Keywords San Joaquin kit fox (Vulpes macrotis mutica) - Noninvasive surveys · Ciervo-Panoche Natural Area $\cdot$ Scat/feces · Landscape genetics $\cdot$ DNA $\cdot$ Detection dog $\cdot$ Population size estimate

Electronic supplementary material The online version of this article (https://doi.org/10.1007/s10592-018-1122-3) contains supplementary material, which is available to authorized users.

Tammy R. Wilbert

tammywilbert@gmail.com

1 Smithsonian Conservation Biology Institute, Center for Conservation Genomics, National Zoological Park, 3001 Connecticut Ave., NW, Washington, DC 20008, USA

2 Environmental Science \& Policy, George Mason University, 4400 University Dr., Fairfax, VA 22030, USA

3 Working Dogs for Conservation, P.O. Box 280, Bozeman, MT 59771, USA

4 Bureau of Land Management, Central Coast Field Office, 940 2nd Avenue, Marina, CA 93933, USA

\section{Introduction}

Informed management decisions require reliable data about the distribution and abundance of an endangered species. When it was listed as endangered in 1967, the San Joaquin kit fox (SJKF; Vulpes macrotis mutica) had been substantially reduced from its historic range, with kit foxes restricted primarily to the western and southern ends of the San Joaquin Valley (U.S. Fish and Wildlife Service 1967, 2010) within the San Joaquin Desert biotic province (Germano et al. 2011). Since then, the status of SJKF throughout much of its current range, particularly in the northern and central portions, has remained poorly known due to a lack of large-scale surveys and many areas where surveys cannot be conducted due to private land ownership (U.S. Fish 
and Wildlife Service 1998, 2010). In 1998, a recovery plan identified three geographically-distinct core populations whose enhanced protection and management was critical to a sound conservation strategy: the Carrizo Plain, western Kern County (including Elk Hills, Buena Vista Valley, and Lokern Natural Area), and the Ciervo-Panoche Natural Area (CPNA; U.S. Fish and Wildlife Service 1998; Phillips 2013). Both the Carrizo Plain and western Kern County are located in the southwest end of the range and are known to have high SJKF densities. The CPNA is a rural area in the central range of the SJKF that has been used mainly for grazing and contains relatively few man-made structures. Although little is known about SJKF in the CPNA, the area contains large portions of habitat with moderate and high suitability for SJKF and is thought to have a substantial fox population (Cypher et al. 2013).

Non-invasive genetic sampling offers an effective way to survey wildlife species, even when rare or endangered (Taberlet et al. 1999; Waits and Paetkau 2005; Ruell and Crooks 2007; Beja-Pereira et al. 2009). DNA obtained from scat samples can be used to identify individuals and estimate population size, alleviating challenges in gathering population data on low density species (Marucco et al. 2009; Solberg et al. 2006). Moreover, detection dogs trained to locate the scat of a specific species can reliably increase sample size(s) and number of observations of both fresh and aged scats (MacKay et al. 2008; Woollett et al. 2014). Conservation dog-handler teams have proven to be a useful tool for detecting SJKF scats, increasing the number of samples recovered in genetic surveys (Smith et al. 2003, 2006; Wilbert et al. 2015).

We used conservation dog-handler teams to locate SJKF scats in the CPNA, followed by DNA analysis of the collected scats. Using the genetic data, we documented the distribution of SJKF in the area and identified individuals present. We assessed genetic diversity and investigated how individuals in the area are related. We tested for population structure and connectivity within the CPNA. We used our data to estimate contemporary effective population size $\left(N_{e}\right)$ as well as demographic or census population size $(N)$. With this new information about SJKF in the CPNA, we discuss the relevance of our findings to the conservation of this population and of the species rangewide.

\section{Materials and methods}

\section{Study area}

The CPNA comprises $\sim 372 \mathrm{~km}^{2}$ of moderate to highly suitable SJKF habitat (Cypher et al. 2013). This area includes the Panoche Hills, Panoche Valley, Griswold Hills, Vallecitos Valley, Tumey Hills and Ciervo Hills, as well as a narrow stretch of habitat east of these hills and west of Interstate 5. Altogether the CPNA represents a large continuous stretch of relatively undisturbed land from Mercy Hot Springs through the Panoche Valley to Silver Creek Ranch, and Vallecitos (Fig. 1). The Panoche Valley (PV) itself was the basin of a Pleistocene lake (Barrows and Ingersoll 1893), resulting in a fertile valley supplied by the Panoche Creek and consisting mainly of grasslands. Like other areas in the San Joaquin Valley, parts of the PV have been used for grazing and cultivation of crops since the mid-1800s (Frusetta 1991). However, the majority of the PV has not been further developed, with many ranchers and farmers living outside of the valley and using the land for livestock grazing or agriculture over the past centuries (Frusetta 1991). Today the PV is a mosaic of land uses with public and private ownership. Ten percent of the land is federally owned and protected from development. Another $105 \mathrm{~km}^{2}(\sim 50 \%)$ are protected through a conservation easement, while approximately $8 \mathrm{~km}^{2}$ are slated for development as a large-scale solar plant. Thus, most of the PV has very suitable habitat for SJKF and is the largest area of land in the northern and central range of the fox that still shows lower levels of human impact.

\section{Surveys}

Between 2009 and 2011, professional conservation detection dog-handler teams (Working Dogs for Conservation, Bozeman, MT) were used to locate scats of kit fox in multiple areas of the CPNA. Survey effort and locations varied each year, and consisted of a combination of targeted repeat and opportunistic surveys, driven by the dual aims of surveying new areas each year and increasing the likelihood of detecting more individuals overall. Several transects covering a total distance of approximately 56, 41, and $24 \mathrm{~km}$ were searched in suitable kit fox habitat in July of 2009, July of 2010, and May of 2011, respectively (Fig. 1). As determined by a freshness rating method based on their physical characteristics (see Smith et al. 2003), both fresh and aged scats were collected for DNA analysis.

The majority of transects were on public properties and right-of-ways, though private lands were also surveyed when access was permitted. Many transect routes utilized unpaved roads, as kit foxes frequently deposit a high number of scats on these roads (Smith et al. 2005). Additionally, various transects (or legs) were in vegetation or alongside paved roads bordering suitable habitat.

In order to augment the overall sample size for genetic analyses, all scats collected from 2009 to 2011 were combined with scats from a separate SJKF monitoring study that several of the co-authors were involved with in the PV area from July to September of 2010. In that study, surveys of approximately $352 \mathrm{~km}$ of transects on two adjacent sites included an initial and a repeat survey session approximately 
Fig. 1 Survey areas and transects (green lines) are demarcated on the topographic map of the Ciervo-Panoche Natural Area (CPNA; purple boundary). Yellow triangles represent all of the scats genetically identified as SJKF and used in the population analyses $(n=330)$ while red circles represent the central location from all scat samples collected from each individual $(n=91)$

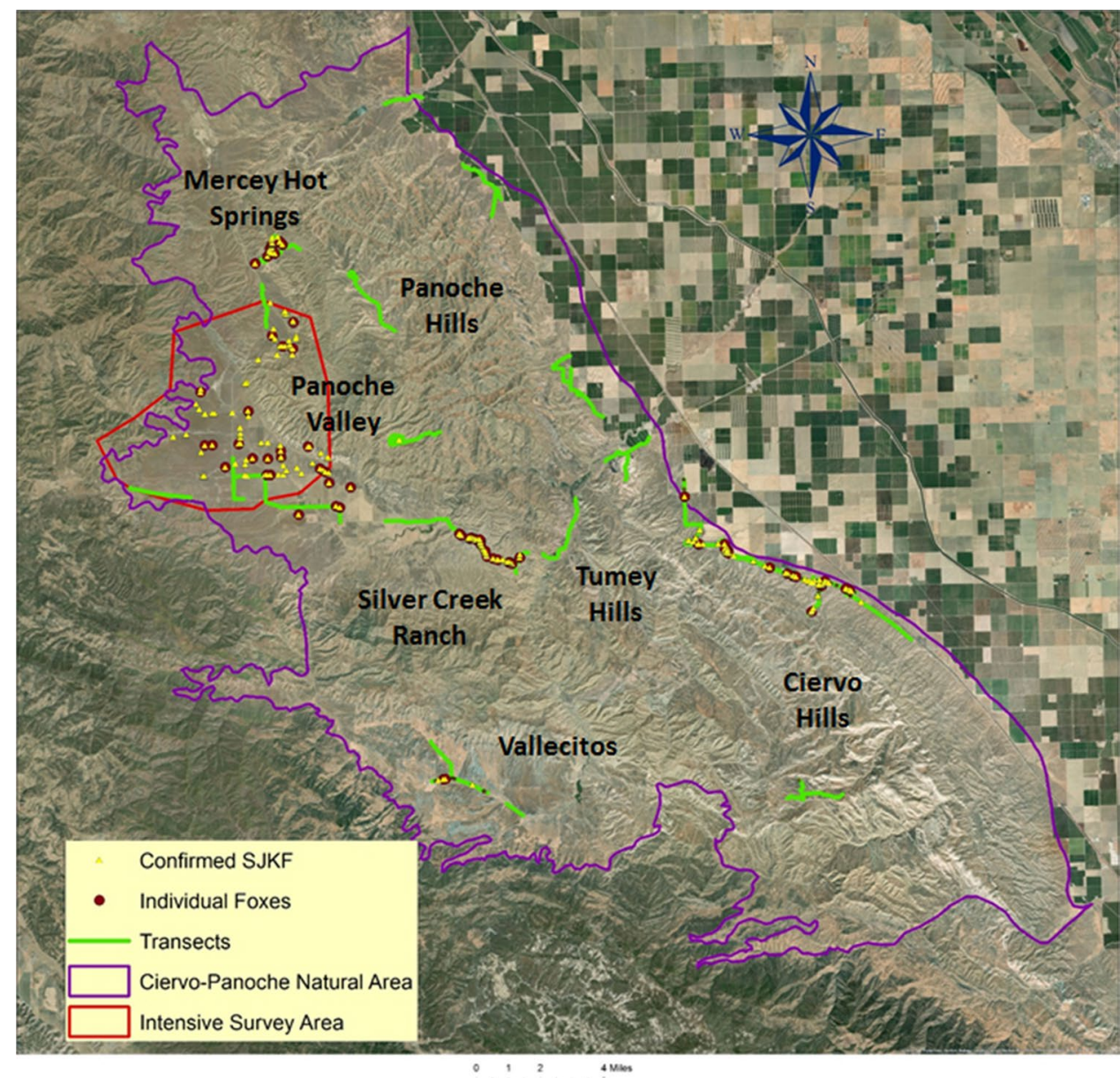

one week apart during which only fresh scats were collected for DNA analysis, since the goal was to obtain current presence and population information. Because that study included different areas, combining data also expanded our understanding of SJKF occupancy across the CPNA.

Locations of all scats were geo-referenced and recorded using Global Positioning System (GPS) units. Scats were stored in plastic bags with silica gel for desiccation (Fisher Scientific, Pittsburgh, PA) and shipped to the Center for Conservation Genomics laboratory at the Smithsonian Institution. All samples were used to map kit fox scat distribution and an individual's recapture area.

\section{Molecular techniques}

DNA was extracted using the QIAamp DNA stool mini kit in a separate room to avoid contamination of PCR products from the main lab. Species identification, molecular sexing, and microsatellite genotyping were conducted following protocols detailed in Wilbert et al. (2015). Although conservation dogs can detect more scats and with greater accuracy in identification of species than humans (Hurt and Smith 2009), a handler may inadvertently collect non-target scat when a dog correctly locates a latrine containing fresh scats from multiple canids (i.e. fox/coyote; Ralls and Smith 2004); when a dog errs in scent discrimination and keys on a similar (yet incorrect) target; or when a dog selects an incorrect target when few target scats are present in order to receive a reward (Schoon 1996; Smith et al. 2003). Therefore, we determined the species of each scat sample by amplifying a fragment of the mitochondrial control region, which is species-specific by size (Bozarth et al. 2010). During this step, we diluted samples with poor amplification (1:15 up to $1: 45$ ) to minimize interference from PCR inhibitors from prey items such as insects (Panasci et al. 2011). These dilutions served as an optimization step for the following molecular steps because amplification issues were usually related to the quality of the scat sample. We then used canidspecific primers that use differences in the zinc finger gene to identify sex - two bands for males and one for females (Ortega et al. 2004; Ralls et al. 2010). Only samples that amplified successfully in both species and sex identification were then characterized for six microsatellites (FH2137, FH2140, FH2226, FH2535, FH2561, Pez19) that have been used reliably for individual identification of kit foxes in our lab (Smith et al. 2006). Because DNA samples extracted 
from scats are prone to genotyping error and contamination, we used a modification of the multi-tube approach (Taberlet et al. 1996). Briefly, each DNA extract was subject to a minimum of five independent PCR amplifications for each homozygous locus and a minimum of three times for each heterozygous locus to verify allele size and detect allelic dropout. Each amplification was conducted with a positive and negative control to detect any contamination and to standardize allele sizes across all data. We used fluorescently labeled forward primers in all PCRs to visualize them on an ABI PRISM* 3130 Genetic Analyzer (Applied Biosystems Inc. Foster City, CA).

We used the Excel Microsatellite Toolkit (Park 2001) to compare genotypes and defined individuals by unique genotypes and samples from the same individual by matching alleles at all loci. We checked all genotypes carefully but paid particular attention to those that differed at only one or two loci for accuracy of genotype and data entry. We also compared genotypes between samples collected in 2009-2011 to determine if any individuals had been recaptured in subsequent years. We checked for evidence of allelic dropout and/or null alleles using the program Micro-Checker (vanOosterhout et al. 2004).

We assessed our ability to differentiate individuals by estimating the probability of identity $\left(P_{I D}\right)$ (i.e. the probability of different individuals sharing an identical genotype by chance) and the $P_{\text {ID }}$ between siblings (Mills et al. 2000; Waits et al. 2001). Both $P_{\text {ID }}$ unbiased and $P_{\text {ID }}$ sibs values were low enough to suggest that we can differentiate between individuals, including close relatives $\left(P_{I D}\right.$ unbiased $=1.4 \times 10^{-5}, P_{\mathrm{ID}}$ sibs $\left.=9.9 \times 10^{-3}\right)$. Because we identified many individuals, we genotyped individuals at 5 additional microsatellites previously characterized in canids (AHTh171, FH2054, FH2328, FH2848, and Ren162; Spiering et al. 2009) to increase our statistical power in subsequent analyses. We selected one representative scat sample that amplified most reliably for each individual and genotyped these samples at the additional loci using the same protocols and conditions described above. We then used the final genotype of 11 microsatellites to assess genetic diversity and population structure.

\section{Genetic diversity}

We used GenAlEx to calculate expected $\left(H_{E}\right)$ and observed $\left(H_{O}\right)$ heterozygosity, and SPAGeDi to calculate allelic richness $\left(A_{R}\right)$ as defined by Nielsen (2003), effective number of alleles $\left(N_{e}\right)$, and global estimates of $F_{I S}$. We tested for departure from Hardy-Weinberg equilibrium with a global test of heterozygote deficiency using the Markov chain method in GenePop 3.4 (Raymond and Rousset 1995). We also used GenePop to test for linkage disequilibrium (LD) between pairs of loci. We calculated relatedness using the mean Queller and Goodnight estimator (1989) in GenAlEx.

\section{Genetic patterns of population structure}

We investigated genetic differentiation and structure within the CPNA through Bayesian analyses and statistical measures of variance. We used three Bayesian clustering approaches to detect population structure in individuals in the CPNA, one non-spatial (STRUCTURE version 2.3.2; Pritchard et al. 2000) and two spatially sensitive (TESS version 2.3.1, Chen et al. 2007; GENELAND version 2, Guedj and Guillot 2011). STRUCTURE assigns genotypes to genetic clusters that maximize Hardy-Weinberg and linkage equilibrium. We investigated the likelihood of the number of genetic clusters $(K)$ from 1 to 8 with 10 independent replicates, admixture ancestry and correlated allele frequency models, and Markov chain Monte Carlo resampling for 400,000 generations following a burn-in of 100,000. We visualized the STRUCTURE results using STRUCTURE Harvester (Earl and vonHoldt 2012) and determined the number of clusters using the Evanno et al. (2005) method. Results from the ten replicates of the chosen $K$ were averaged using CLUMPP 1.1.2 (Jakobsson and Rosenberg 2007) and the appropriate .ind file created from Harvester. We assigned individuals to a cluster if they had an ancestry assignment of at least 0.70, following Marsden et al. (2012).

The spatially sensitive analyses, TESS and GENELAND, use the same principles as STRUCTURE but also incorporate the geographic coordinates for each individual. Because we found two or more scats for many individuals and there are no programs that can incorporate more than one geographic location per individual for this type of analysis, we chose one GPS point for each individual that was located in the middle of its sample distribution. When an individual had only two scat locations, we chose the point that was closer to other individuals. In TESS, we analyzed our data using the default geospatial weighting of 0.6 , and analyzed values of $K$ from 1 to 10, with 10,000 burn-in sampling and 50,000 recorded steps. Each potential population was run 10 times for three models: no admixture (HMRF model), the CAR admixture model, and the BYM admixture model. The most appropriate number of populations was chosen using the highest $30 \%$ DIC scores for all runs and looking at two indicators: (1) determining the lowest value, and (2) graphing the average DIC scores for each model as the value of $K$ increased. In GENELAND, we ran the correlated frequency model for 500,000 steps with every 100th step recorded and a burnin of 100,000 steps. This model was run for 10 replicates of 1-10 populations.

We performed a hierarchical analysis of molecular variance (AMOVA) using GenAlEx to test for the proportion of genetic variation between subpopulations previously 
identified using STRUCTURE. We tested the significance of the percentage of variance between and within populations using an F-test. We calculated the F ratio and probability of variance in Excel using 1 degree of freedom for the numerator (number of groups, $K,-1$ ) and 180 degrees of freedom for the denominator (total sample size equals two alleles per individual -2 ). We visualized genetic differentiation with a principal coordinate analysis (PCoA) conducted in GenAlEx. We also calculated the mean eigenvalues for principal coordinates 1 and 2 for both populations and plotted this mean on the PCoA to display the population separation. Using GenAlEx, we also calculated two measures of genetic differentiation: $F_{S T}$ as described by Slatkin (1995) and $D_{e s t}$ (Jost 2008) as calculated by Meirmans and Hedrick's equation 2 (2011).

To examine alternative causes for genetic structure, we tested for isolation by distance (IBD) and kin clustering. We generated matrices of genotypic distance (GD) and linearized geographic distance (LnGGD). We executed Mantel tests between GD and LnGGD with 10,000 permutations to test for IBD. We created matrices of pairwise relatedness using the mean Queller and Goodnight estimator (Queller and Goodnight 1989) and tested for correlation with LnGGD using the same Mantel test parameters. We also performed a spatial autocorrelation analysis (SAA) to see if individuals next to each other were more related than average, which would be expected because kit foxes live in family groups (Cypher et al. 2000), and at what spatial scale this kin clustering might occur. SAA is a multivariate analysis that measures the genetic similarity of individuals within a distance class. We chose a distance class of $2 \mathrm{~km}$ because we needed the ability to detect fine scale structure resulting from family groups inhabiting typical SJKF home ranges of $4-11 \mathrm{~km}^{2}$ (Cypher et al. 2000; Koopman et al. 2000). The autocorrelation coefficient $(r)$ ranges from -1 to +1 and is closely related to Moran's I, a measure of genetic relatedness. We ran SAA in GenAlEx using 10,000 bootstraps around $r$ and 10,000 permutations to calculate the $95 \%$ upper and lower confidence limits of random sampling of the data assuming no spatial structure. Heterogeneity of spatial structure (omega) was used to test significance of the correlogram.

\section{Population estimates}

We used two methods to calculate $N_{e}$ : an $N_{e}$ estimator based on sibship frequency (SF; Wang and Santure 2009) as implemented in the program COLONY (Jones and Wang 2010), and the commonly used LD method (Hill 1981; Waples and Do 2008) as implemented in NeEstimator v.2.01 (Do et al. 2014) with a correction for bias from low frequency alleles (Waples 2006). These are the most robust methods available to estimate $N_{e}$ from one sample. We could not use two-sample methods because they require samples collected at least 3-5 generations apart for species with overlapping generations (Waples and Yokota 2007). For both methods, we used the random mating model. We calculated $N_{e}$ using individuals that were detected during all 3 years since this period represents 1-2 kit fox generations. While combining years, we calculated $N_{e}$ for each subpopulation separately because combining them would violate population closure, which is assumed by the models in these programs $\left(N_{e}\right.$ calculations that combined the subpopulations showed a Wahlund effect as expected; data not shown). For $N_{e}$ estimates based on SF, we assumed polygamy for males and females and used the population allele frequencies, no sibship prior, two medium length runs with the full-likelihood method, and we report $95 \%$ confidence intervals. For the LD estimate, we used a minimum allele frequency cutoff $\left(P_{c r i t}\right)$ of 0.02 , which is suggested for our sample sizes in order to balance $N_{e}$ precision and upward bias from rare alleles (Waples and Do 2010). We report $95 \%$ confidence intervals from the jackknife approach.

We also explored possible bias in LD-based $N_{e}$ estimates due to immigration or the presence of highly related individuals (Waples and Anderson 2017). Because scat samples do not allow us to directly determine the age of individuals nor definitive kinship relationships, we performed this analysis using three subsets of data: (1) all individuals from a population, (2) individuals from a population without those identified as migrants or genetically admixed, and (3) individuals from a population without those that were highly related. We removed migrants or genetically admixed individuals that were identified previously with STRUCTURE. We used the Queller and Goodnight estimator to calculate pairwise relatedness between individuals and removed the smallest number of individuals required to reduce pairwise relatedness to $<0.5$.

We calculated census population size $(N)$ using two methods: (1) Capwire (Miller et al. 2005) and (2) inference from $N_{e} / N$ ratios. Capwire uses the number of samples per individual to estimate detection probability and then runs urn simulations to estimate population size using two capture probability models - the equal capture probability (ECM) and the two innate rates model (TIRM). The appropriate model is chosen using a likelihood-ratio test. TIRM is used when capture rate is heterogeneous between individuals. We calculated a population estimate for each subpopulation for all 3 years combined (with and without highly related individuals), as well as for each subpopulation for each year. We did not calculate $N$ for each subpopulation for each year without highly related individuals because our sample sizes were too small.

To estimate $N$ from $N_{e} / N$ ratios, we used the $N_{e}$ estimates for the full dataset (individuals over all 3 years for each subpopulation) from the SF method (from COLONY, see above) because it is more robust than the LD estimator to violations 
of model assumptions such as random sampling and nonrandom mating (Wang 2016). In addition, the $N_{e}$ values from the SF estimator were slightly lower and therefore would produce a more conservative number of individuals. Previous research showed that the harmonic mean of the $N_{e} / N$ ratio was 0.55 for kit fox at the Naval Petroleum Reserves in California (Otten and Cypher 1998). However, these authors suggested using an $N_{e} / N$ ratio of $0.2-0.3$ to be conservative. A meta-analysis of life history traits across taxa suggested $N_{e} / N=0.76$ for a similar species, the gray fox (Waples et al. 2013). Therefore, we calculated $N$ using $N_{e} / N=0.55$ and bounded our estimate with a low $N_{e} / N$ of 0.25 (and thus higher inferred $N$ ) and a high $N_{e} / N$ of 0.76 (and thus lower inferred $N$ ).

\section{Results}

We collected a total of 597 scat samples (aged and fresh): 159 scats in 2009, 344 in 2010, and 94 in 2011. We were able to isolate mitochondrial DNA from $69 \%(n=411)$ of the total scat samples, of which 398 or $97 \%$ were confirmed as SJKF. We assigned 332 samples to unique genotypes, identifying 93 individuals, 56 males and 37 females, giving a 1:0.66 sex ratio. Half of the individuals carried a mtDNA haplotype with the length of $252 \mathrm{bp}$, which is found in all SJKF in other locations (Wilbert et al. 2015), while the other half possessed a regionally unique haplotype with a $16 \mathrm{bp}$ deletion (236 bp; Table 1). We collected an average of 3.6 scats per individual, although we found 10-20 scat samples for a few individuals. We recaptured four individuals in 2009 and 2010 and four individuals in 2010 and 2011. One female was found every year although we only found six of her scats. SJKF scats were found in the central Panoche Valley, Mercy Hot Springs, Silver Creek Ranch, the eastern foothills of the Tumey and Ciervo Hills, and the Vallecitos area (Fig. 1).

We only included individuals for the population analysis that we could confidently genotype for at least 8 of the 11 microsatellite loci. We had high-quality data for 91 individuals ( $\mathrm{n}_{8}=3, \mathrm{n}_{9}=5, \mathrm{n}_{10}=10, \mathrm{n}_{11}=74$; from 330 scat samples) that we used in all subsequent analyses. We found moderate levels of heterozygosity $\left(H_{O}=0.576 \pm 0.055\right.$, unbiased $H_{E}=0.641 \pm 0.048$; Table 1). Microsatellite loci had 4-13 alleles per locus and we found no evidence of large allelic dropout at any locus. Potential null alleles were indicated by an excess of homozygotes at two microsatellite loci (AHTh171 and FH2848). However, these calculations may have been affected by missing data as these loci could not be genotyped in $10 \%$ of the individuals. Allelic richness was 7.79 and the effective number of alleles was 3.18. The global estimate of $F_{I S}$ for the overall population was 0.100 . The CPNA was not in Hardy Weinberg (HW) equilibrium due to heterozygote deficit $(p=0.0001)$.

Bayesian clustering analysis in STRUCTURE indicated strong population subdivision, with the $\Delta K$ statistic (Evanno et al. 2005) showing a peak at $K=2$ (Supplemental Fig. 1). Cluster 1 was comprised of individuals located in the Panoche Valley (west of the Panoche and Tumey Hills) including individuals at Silver Creek Ranch and along Little Panoche Road through Mercy Hot Springs. Cluster 2 included individuals on the eastern slope of the Tumey Hills and Ciervo Hills, between the foothills and I-5. Using the ancestry assignments of at least $70 \%$ with 10 replicates, 56 individuals were assigned to cluster 1 and 22 were assigned to cluster 2 . Two of the individuals assigned to cluster 1 were located to the east of the Ciervo Hills and two individuals from cluster 2 were located in the Panoche Valley (asterisks in Fig. 2b). We classified these four individuals as putative migrants. We found 13 individuals with mixed ancestry (between 30 and 70\%) that were assigned to the location where they were found, including 12 located in the valley and one to the east of the Ciervo Pass. These migrants and individuals of mixed ancestry are delineated in Fig. $2 \mathrm{~b}$ by a dashed line separating the individuals with $>70 \%$ ancestry. We found the same number of migrants and admixed individuals if we modified the STRUCTURE cutoff values from $70 \%$ assignment to the $80 \%$ used by Crawford et al. (2009) and Cullingham et al. (2009) or the $60 \%$ used by Coulon et al. (2008).

Population structuring differed slightly between STRU CTURE and the spatially explicit programs, TESS and
Table 1 Measures of genetic diversity in the Panoche Valley and I-5 populations

\begin{tabular}{|c|c|c|c|c|c|c|c|c|c|}
\hline \multirow[t]{2}{*}{ Population } & \multicolumn{6}{|c|}{ Microsatellites } & \multicolumn{3}{|c|}{ mtDNA haplotype } \\
\hline & $A_{R}$ & $N_{e}$ & $H_{E}$ & $H_{O}$ & $F_{I S}$ & QG & $236 \mathrm{bp}$ & $252 \mathrm{bp}$ & No amp \\
\hline Panoche Valley $(n=68)$ & 6.72 & 3.065 & 0.612 & 0.564 & 0.074 & -0.017 & 29 & 36 & 3 \\
\hline $\mathrm{I}-5(n=23)$ & 5.50 & 2.764 & 0.617 & 0.612 & 0.011 & -0.043 & 11 & 5 & 7 \\
\hline Total $(n=91)$ & 7.79 & 3.136 & 0.641 & 0.576 & 0.100 & -0.012 & 40 & 41 & 10 \\
\hline
\end{tabular}

Mitochondrial DNA haplotypes indicate the number of individuals with each haplotype (236 bp, $252 \mathrm{bp}$, or no amplification) from species identification

$A_{R}$ allelic richness, $N_{e}$ number of effective alleles, $H_{E}$ unbiased heterozygosity, $H_{O}$ observed heterozygosity, $F_{I S}$ fixation index, $Q G$ the mean Queller and Goodnight estimator 


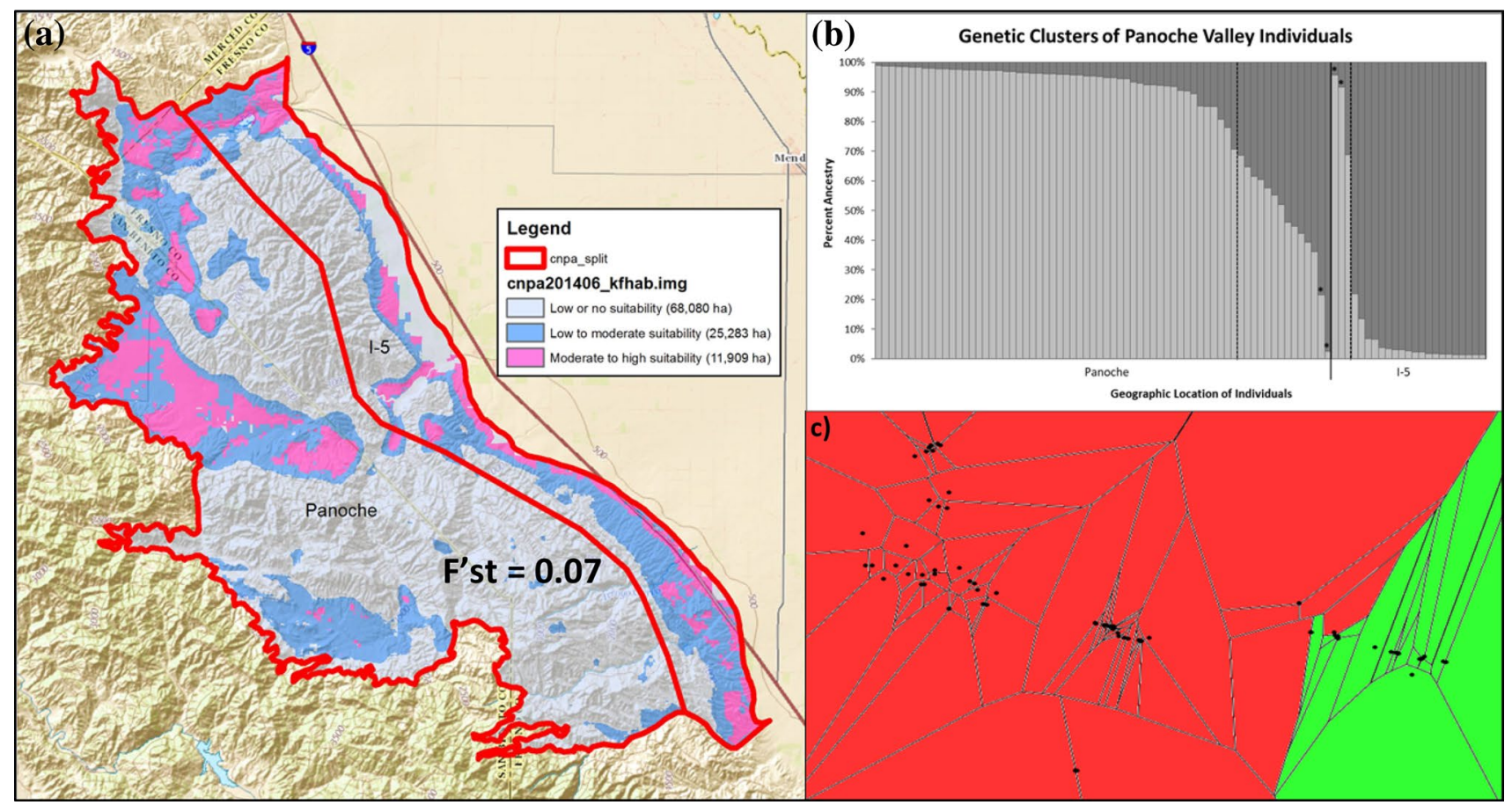

Fig. 2 Two defined kit fox subpopulations within the CPNA. a Habitat suitability of the CPNA (figure created by Scott Phillips based on data compiled for Cypher et al. 2013) split into two areas that relate to the two genetically distinct kit fox groups. b Percent ancestry of each individual $(n=91)$ identified by Structure; Cluster 1 in light grey and Cluster 2 in dark grey, separated by a black solid line. The dotted

GENELAND. TESS detected two subpopulations with 71 individuals in cluster 1 and 20 individuals in cluster 2 (Fig. 2c). TESS combined all individuals detected in the Panoche Valley (cluster 1) with the two migrant individuals from cluster 2 into one group. GENELAND supported the same structuring found by TESS, assigning higher posterior probabilities for migrants and mixed ancestry to the location of sampling (results not shown). These differences from STRUCTURE may be expected due to the nature of their algorithms and the biological importance of geographic isolation. When TESS used spatial information to assign individuals to clusters, it tended to assign individuals to the locations where they were sampled and was biased to assign individuals to cluster 1 . In subsequent analyses, we compared the two geographically designated subpopulations - the Panoche Valley (PV, $n=68)$ and the I-5 $(n=23)$, with mixed ancestry and migrant individuals assigned to the group where the samples were collected. The geographic areas inhabited by these two subpopulations are shown in Fig. 2a with the split between them based on high elevation (Scott Phillips personal communication), which is likely a barrier to kit fox movements.

Separation between individuals in the PV and I-5 was also supported by statistical measures of variance. The lines represent a 70\% cutoff, where by individuals are either admixed or migrants (asterisks) if they are located between the dotted line and the solid line. c Clustering of individuals $(n=91)$ from TESS using geospatial weighting and the clear division that corresponds to the ridgeline

hierarchical AMOVA found 10\% variance between populations and $90 \%$ within populations. The one-tailed F-test of variance of the AMOVA detected significant differentiation between subpopulations $\left(F=8.892, F_{1,180}<0.003\right)$. The first two coordinates of the PCoA represented $47.8 \%$ of the total variation (coordinate $1=31.0 \%$, coordinate $2=16.8 \%$; Supplemental Fig. 2). Measures of genetic differentiation also showed significant separation between the two subpopulations: $F^{\prime}{ }_{S T}=0.278$ and Jost's $D=0.190$ (all $p<0.0001$ ).

Mantel tests showed a weak but significant correlation between genetic diversity and geographic distance, even within subpopulations (CPNA: $r=0.200, p<0.0001$; PV: $r=0.111, p<0.013 ; \mathrm{I}-5: r=0.225, p<0.003)$. Mantel tests showed a significant negative correlation between relatedness and geographic distance (CPNA: $r=-0.314$, $p<0.0001$, PV: $r=-0.180, p<0.0001 ; \mathrm{I}-5: r=-0.325$, $p<0.0001)$. Spatial autocorrelation analysis of all SJKF in the CPNA area indicated that individuals within $6 \mathrm{~km}$ of each other are significantly more related than average $(p<0.0001$; Fig. 3). Estimates of relatedness across the CPNA and within each subpopulation were similarly low; for example, the Queller and Goodnight relatedness estimate for the CPNA was -0.012 (QGM), PV $=-0.017$, and I-5 $=-0.043($ Table 1$)$. 


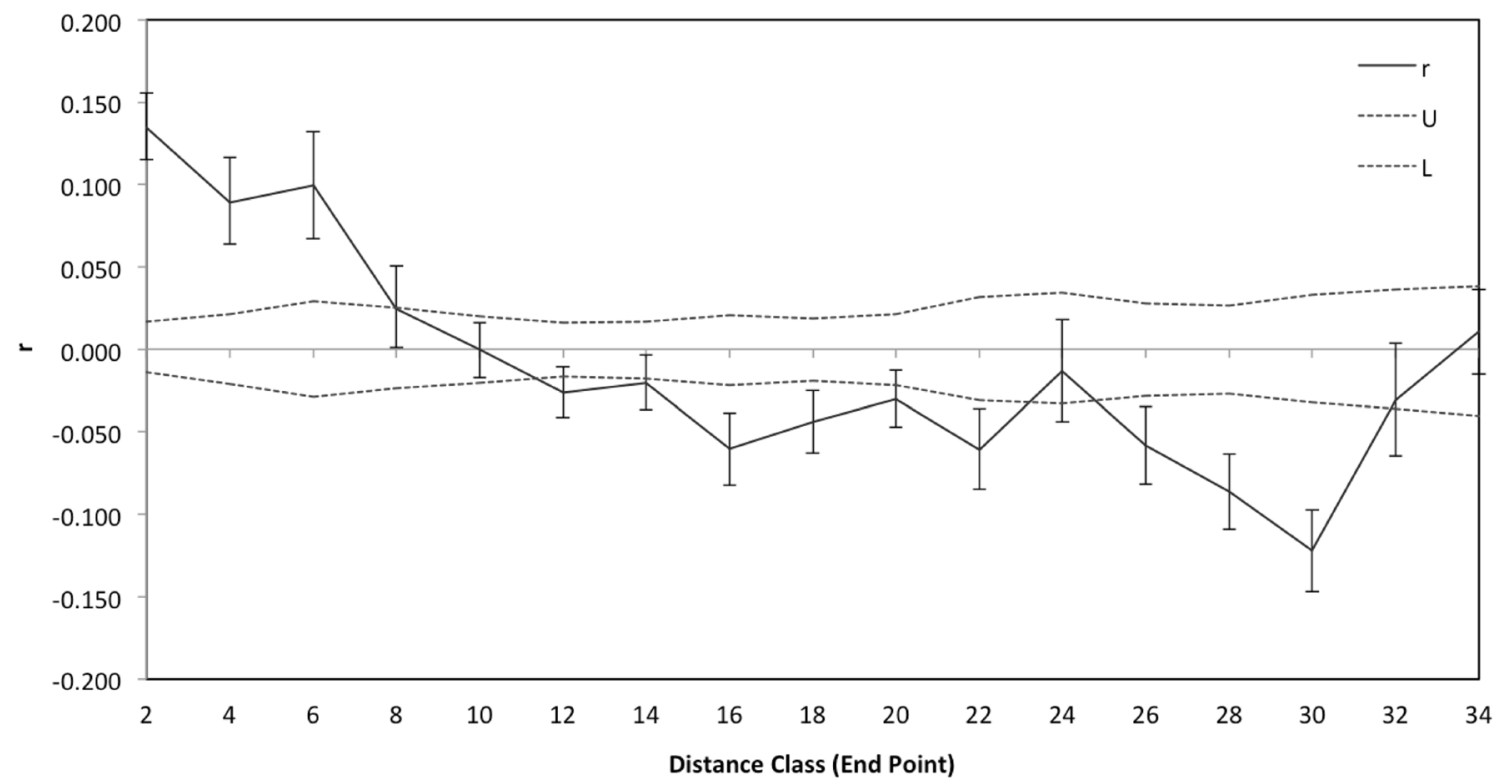

Fig. 3 Spatial autocorrelation analysis of SJKF in the CPNA shows that individuals within $6 \mathrm{~km}$ of each other are significantly more related than average $(p<0.0001)$. The autocorrelation coefficient $(r)$, shown in solid line, represents the genetic similarity of individuals

Genetic diversity was similar between the two subpopulations. The PV subpopulation had 3-11 alleles per locus with $A_{R}=6.72$ and 3.12 effective number of alleles. The I-5 subpopulation had 3-9 alleles per locus with $A_{R}=5.50$ and 2.87 effective number of alleles. Expected and observed heterozygosities were lower for each subpopulation as compared to the overall CPNA (see Table 1). The $F_{I S}$ value for PV was higher (0.08) than I-5 (0.01), but both were lower than overall CPNA $F_{I S}=0.103$. Tests in Genepop showed the I-5 subpopulation is in HW and linkage equilibrium. However, the PV subpopulation had 3/55 pairs of loci showing LD. There was no evidence that any particular locus was more often involved in linkage and three significant tests are expected by chance at the 0.05 level $(0.05 \times 55=3)$.

Table 2 Estimates of effective population size $\left(N_{e}\right)$ based on linkage disequilibrium (LD) calculated with NeEstimator with $P_{\text {crit }}=0.02$, the random mating model, and confidence intervals from jackknifing, within a distance class. The dotted lines signify the upper (U) and lower (L) bounds of the $95 \%$ confidence interval of a random distribution of the data

We created subsets of our data to look at potential influences on the estimates of $N_{e}$. Mean relatedness across each subpopulation did not change appreciably when we removed individuals that had mixed ancestry or were identified as migrants, nor when we removed highly related pairs (see Supplemental Table 1). However, removal of these individuals greatly changed the estimates of $N_{e}$ (Table 2). When we removed individuals that showed mixed ancestry or identification to the other population, $N_{e}$ was reduced, which is expected because we removed the genetic diversity of individuals from the other subpopulation. When we removed individuals that were highly related, the estimate of $N_{e}$ increased, which is also expected because a smaller number of individuals

\begin{tabular}{llrr}
\hline & \# Individuals & LD $N_{e}$ & SF $N_{e}$ \\
\hline Panoche Valley (West) & & & \\
Overall & 68 & $44(27-85)$ & $36(23-60)$ \\
Without mixed ancestry or migrants & 54 & $40(27-68)$ & $27(17-47)$ \\
Without highly related individuals & 45 & $109(45-\infty)$ & $31(18-51)$ \\
I-5 (East) & & & $12(6-27)$ \\
Overall & 23 & $9(11-24)$ & $11(6-26)$ \\
Without mixed ancestry or migrants & 20 & $80(29-\infty)$ & $15(7-38)$ \\
Without highly related individuals & 16 & &
\end{tabular}


contained a comparable amount of genetic diversity as the full dataset.

In estimating census size $(N)$, we first used the number of times that an individual was resampled to estimate the subpopulation size of each year with the program Capwire. The TIRM model, which indicates capture heterogeneity, was selected by the program as the most likely model of capture probability for each year and subpopulation. The average number of scat samples per individual per year in both subpopulations was $>1.7$, which was the minimum level of resampling to produce accurate Capwire results in grey wolves (Stenglein et al. 2010; Stansbury et al. 2014). As survey effort and locations varied each year, the estimated subpopulation size varied across each year and no year was representative of the total number of individuals in either location (Table 3).

We then estimated the number of individuals across all 3 years using Capwire and extrapolated the number of individuals from $N_{e} / N$ ratios, with and without highly related individuals. The number of individuals estimated in the Panoche Valley ranged from 60 to 90, while the number of individuals in the I-5 ranged from 17 to 27 (Fig. 4). The Capwire estimates have smaller confidence intervals due to less variation in urn model simulations, while the large confidence intervals around estimates from $N_{e} / N$ method result from the use of $N_{e} / N$ ratios with and without migrant and admixed individuals and close relatives. Because Capwire uses recapture rates to estimate size, the combination of both subpopulations (overall CPNA) will make variation across recapture rates lower, which in turn will make the population appear to be more thoroughly surveyed than it actually was and the estimates low. Additionally, the yearly subpopulation estimates are low because all areas were not surveyed in any given year. Population estimates extrapolated from $N_{e}$ for the entire CPNA display a Wahlund effect, as expected from

Table 3 Estimates of census population size $(N)$ calculated using Capwire for each year in each population. Capwire estimates are reported with $95 \%$ confidence intervals in parentheses

\begin{tabular}{lccllc}
\hline Location & Year & $\begin{array}{c}\text { \# Scats fully } \\
\text { genotyped }\end{array}$ & $\begin{array}{l}\text { Minimum \# } \\
\text { individuals }\end{array}$ & Ave \# Scat/Ind & N estimate (Capwire) \\
\hline Panoche Valley & 2009 & 31 & 17 & 1.8 & $32(17-46)$ \\
Panoche Valley & 2010 & 114 & 37 & 3.1 & $43(37-54)$ \\
Panoche Valley & 2011 & 53 & 20 & 2.7 & $28(20-38)$ \\
I-5 & 2010 & 106 & 20 & 5.3 & $22(20-25)$ \\
I-5 & 2011 & 26 & 6 & 4.3 & $6(6-7)$ \\
\hline
\end{tabular}

Not all areas were surveyed in any given year

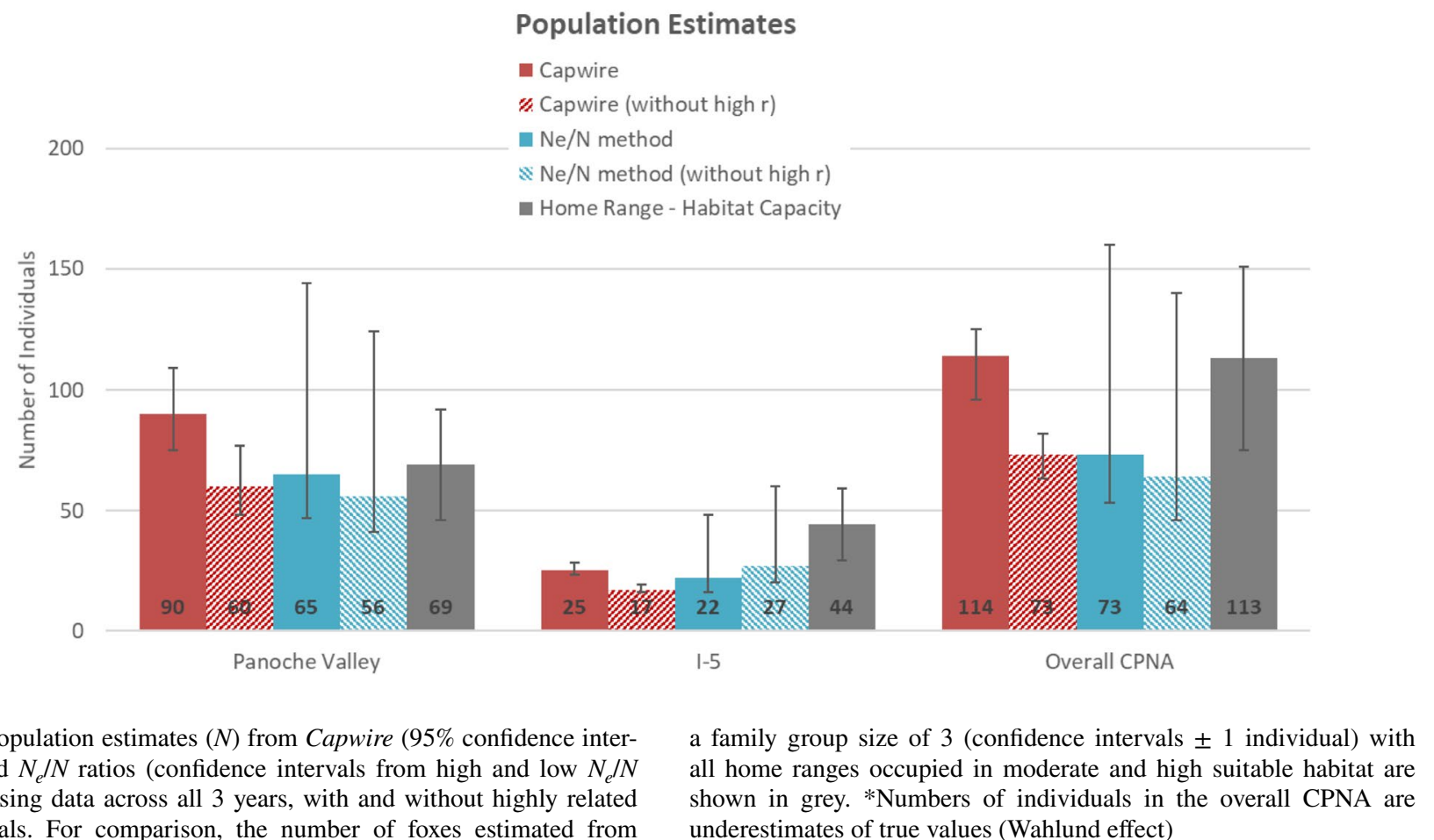

Fig. 4 Population estimates $(N)$ from Capwire (95\% confidence intervals) and $N_{e} / N$ ratios (confidence intervals from high and low $N_{e} / N$ ratios) using data across all 3 years, with and without highly related individuals. For comparison, the number of foxes estimated from a family group size of 3 (confidence intervals \pm 1 individual) with underestimates of true values (Wahlund effect) 
the inclusion of genetically differentiated subpopulations (Fig. 4).

\section{Discussion}

Non-invasive sampling can be difficult due to low quality and low quantity DNA that leads to low amplification rates (Taberlet et al. 1999; Waits and Paetkau 2005; Beja-Pereira et al. 2009). Despite a broad range in quality of scat samples used in this study, we successfully obtained species information on $69 \%$ of all scats (both aged and fresh). As we expected, and found in other fecal DNA studies (DeMatteo et al. 2014; Panasci et al. 2011; Piggott 2004; Santini et al. 2007), fresh scat had higher success downstream in the genetic analysis (important in studying population dynamics) but aged scat was very useful in identifying kit fox presence. Even when being conservative in classifying scat samples as SJKF and demanding clear and consistent data before assigning a unique genotype, we were able to identify 398 scats to kit fox and ascertain 93 individuals.

Species identification based on mtDNA showed that SJKF in this area had two control region haplotypes of different fragment sizes, with half of the individuals carrying each type. These are the only two haplotypes that have been found in SJKF (Wilbert et al. 2015). The smaller 236 bp haplotype has only been found in one individual outside of the CPNA (Wilbert et al. 2015), suggesting that this haplotype is largely restricted to the CPNA.

We identified two male SJKF individuals in the Vallecitos area, one in 2010 and one in 2011. The presence of these two males is significant because the last official sighting of kit fox in the area occurred in the 1970s. Two other samples from Vallecitos had mixed genetic signatures of SJKF and coyote but we could not determine if this was due to crosscontamination in the field, or evidence of a coyote preying on a kit fox or a kit fox scavenging on a coyote.

Multiple analyses consistently split our individuals into two subpopulations, one in the PV and one in the strip of habitat between I-5 and eastern side of the Tumey and Ciervo Hills. The degree of genetic differentiation is large and unexpected given the small geographic scale of this study, but some degree of differentiation has also been observed within the region in other San Joaquin Desert species (Richmond et al. 2017; Statham et al. 2018). The PV and the I-5 area are partially separated by a geographic barrier to kit fox dispersal because of high elevation and unsuitable habitat, but there is a pass at the base of the Tumey and Panoche Hills that connects the two areas at a low elevation with habitat that appears to be suitable for kit foxes. No SJKF scat samples were found on transects searched in this connecting habitat but handlers visually observed scats of coyotes (Canis latrans) in this zone, and red foxes (Vulpes vulpes), gray foxes (Urocyon cinereoargenteus) and bobcats (Lynx rufus) may be present in the area. Larger carnivores using this area may displace or kill most kit foxes that move into or through it (Cypher et al. 2000; Cypher and Spencer 1998; Nelson et al. 2007; Ralls and White 1995; Spiegel and Tom 1996).

However, our analyses indicate that the two subpopulations are still biologically connected. While a handful of migrants were identified in each subpopulation (PV and I-5), most of the admixed individuals were located in the PV population. This suggests that dispersing individuals may have greater ability to move westward than eastward, or that migrants are more likely to survive if they move into the valley.

The CPNA is one of three core SJKF populations and it is geographically isolated from other relatively larger SJKF populations. Our surveys were designed to detect kit fox in as many locations as possible, not to estimate population size. However, we calculated several estimates from our data for the conservation management of this endangered species. We identified a minimum of 93 individuals in the CPNA over the 3 years of surveys, though all areas were not surveyed in any given year. Population estimates from Capwire and $N_{e} / N$ ratios suggest there are about 60-90 individuals in the Panoche Valley subpopulation and 17-27 individuals in the I-5 subpopulation, giving an overall estimate of 73-114 individuals across the CPNA (Fig. 4).

For comparison, we also calculated how many foxes could inhabit the CPNA based on the amount and quality of habitat. Nelson et al. (2007) estimated that $6 \mathrm{~km}^{2}$ are required for each kit fox family group in optimal habitat, so the total CPNA could support 225 kit foxes at most. However, Cypher et al. (2013) found only $65 \%$ of the CPNA contains habitat with moderate or high suitability for kit foxes, and that family groups require a home range of $16 \mathrm{~km}^{2}$ in moderately suitable habitat, which corresponds well to our finding of highly related individuals - potential family groups - within a $6 \mathrm{~km}$ distance. If all home ranges are occupied with a kit fox pair, the area could support a total of 38 kit fox pairs, 23 in the PV and 15 in the I-5 area (Fig. 2a). We multiplied the probable number of pairs in each subpopulation by three as a conservative estimate that represents two adults and one surviving pup, which seems reasonable given the surveys were conducted during the late spring to early fall (May-September), a time of year when many pups were still with their parents (Koopman et al. 2000). This produces an estimate of 69 individuals in PV and 44 in the I-5 area, which corresponds closely to the genetic population estimates (Fig. 4).

Kit foxes are seasonal breeders and are known to have fluctuating population sizes during the year. There are higher numbers of foxes in the spring and early summer due to the presence of adults and their offspring and smaller numbers of foxes in the winter after high juvenile mortality rates during 
dispersal in late summer and fall (up to 65\%, Koopman et al. 2000). This population fluctuation has been documented in long-term spotlighting data (Ralls and Eberhardt 1997). In addition to these within-year differences in population size, there are also between-year variations in population size due to varying precipitation levels that influence kit fox reproduction through a trophic cascade of resource availability (Standley et al. 1992; White and Ralls 1993; Williams and Germano 1992; Cypher et al. 2000). Our Capwire analysis detected heterogeneous capture rates (as indicated by the TIRM model), which may reflect changing numbers of kit foxes at different times of the year and at different locations. Because our surveys were conducted from the late spring to early fall (May-September), our higher estimates of $N$ based on all individuals detected probably better reflect the numbers of foxes present during our surveys while the lower estimates after removing relatives probably better reflect the number of breeding adults (Fig. 4).

Our estimate of roughly 90 kit foxes in the CPNA provides a baseline for future comparisons. In addition, our estimates suggest that most, if not all, of the suitable habitat for kit fox in this area is occupied. This is significant for three reasons. First, small populations are vulnerable to extirpation from ecological events, demographic fluctuations, or human activity. Only a few kit foxes are thought to exist in areas adjacent or near the CPNA so if the current population were lost, reestablishment by natural immigration would not be rapid. Secondly, we found that this population has a unique mtDNA haplotype not found in other locations, and further studies may discover more genetic distinctions. Finally, although we recognize that populations fluctuate in size, we were surprised to find a substantial population that was close to carrying capacity. Other areas in the central portion of SJKF range, such as the San Luis Reservoir in western Merced County, also have medium and high suitable kit fox habitat (Cypher et al. 2013). More extensive surveys in nearby areas with suitable habitat might reveal the presence of SJKF and determine whether or not foxes disperse between the small pockets of suitable habitat adjacent to the CPNA. Our results highlight the importance of continued conservation efforts to preserve SJKF habitat in the CPNA as well as connectivity between the two subpopulations in this area.

Furthermore, habitat connectivity across the entire range of SJKF is important because the majority of SJKF inhabit the southern portion of the range. The other two core areas are very different from the CPNA; they are located in the southern portion of the range, have much more suitable habitat, higher numbers of individuals, and are close to many other areas with SJKF (Cypher et al. 2013). The CPNA is a small population with unique genetic diversity that is largely isolated from other SJKF. When possible, efforts should be made to reduce habitat fragmentation throughout the range of the SJKF, for example by restoring unproductive farmlands to more natural conditions (Cypher et al. 2013; Lortie et al. 2018), thus improving connectivity between the CPNA and other areas to the south with large areas of highly suitable SJKF habitat.

Acknowledgements The U.S. Bureau of Land Management - Central Coast Field Office financially supported sample collection by Working Dogs for Conservation (contract L09PX00630) and laboratory work by the Smithsonian Conservation Biology Institute (contract L09PX00685). We thank R. Cooper, G. Hill, and A. Fesnock for field assistance, and Aimee Hurt for providing exceptional help with dog handling. We thank the members of the Center for Conservation Genomics for their support and guidance, particularly Dr. Robert Fleischer and Nancy McInerney. We are also grateful to Dr. Robin Waples for his advice on estimating effective population size and Dr. Scott Phillips for providing data on habitat suitability and creating Fig. 2a. Finally, we thank the conservation dogs who worked so hard to find kit fox scat!

Open Access This article is distributed under the terms of the Creative Commons Attribution 4.0 International License (http://creativeco mmons.org/licenses/by/4.0/), which permits unrestricted use, distribution, and reproduction in any medium, provided you give appropriate credit to the original author(s) and the source, provide a link to the Creative Commons license, and indicate if changes were made.

\section{References}

Barrows HD, Ingersoll LA (1893) A memorial and biographical history of the coast counties of central California. Lewis Publishing Co., Chicago

Beja-Pereira A, Oliveira R, Alves PC, Schwartz MK, Luikart G (2009) Advancing ecological understandings through technological transformations in noninvasive genetics. Mol Ecol Resour 9:1279-1301

Bozarth CA, Alva-Campbell YR, Ralls K, Henry TR, Smith DA, Westphal MF, Maldonado JE (2010) An efficient noninvasive method for discriminating among faeces of sympatric North American canids. Conserv Genet Resour 2:173-175

Chen C, Durand E, Forbes F, François O (2007) Bayesian clustering algorithms ascertaining spatial population structure: a new computer program and a comparison study. Mol Ecol Notes 7(5):747-756

Coulon A, Fitzpatrick JW, Bowman R, Stith BM, Makarewich CA, Stenzler LM, Lovette IJ (2008) Congruent population structure inferred from dispersal behaviour and intensive genetic surveys of the threatened Florida scrub-jay (Aphelocoma corrulescens). Mol Ecol 17:1685-1701

Crawford JC, Liu Z, Nelson TA, Nielsen CK, Bloomquist CK (2009) Genetic population structure within and between beaver (Castor canadensis) populations in Illinois. J Mammal 90:373-379

Cullingham CI, Kyle CJ, Pond BA, Rees EE, White BN (2009) Differential permeability of rivers to raccoon gene flow corresponds to rabies incidence in Ontario, Canada. Mol Ecol 18:43-53

Cypher BL, Spencer K (1998) Competitive interactions between coyotes and San Joaquin kit foxes. J Mammal 79:204-214

Cypher BL, Warrick GD, Otten MRM, O'Farrell TP, Berry WH, Harris CE, Kato TT, McCue PM, Scrivner JH, Zoellick BW (2000) Population dynamics of San Joaquin kit foxes at the naval petroleum reserves in California. Wildl Monogr 145:1-43 
Cypher BL, Phillips SE, Kelly PA (2013) Quantity and distribution of suitable habitat for endangered San Joaquin kit foxes: conservation implications. Canid Biol Conserv 16:25-31

DeMatteo KE, Rinas MA, ArgÜelles CF, Holman BE, Di Bitetti MS, Davenport B, Parker PG, Eggert LS (2014) Using detection dogs and genetic analyses of scat to expand knowledge and assist felid conservation in Misiones, Argentina. Integr Zool 9:623-639

Do C, Waples RS, Peel D, Macbeth GM, Tillett BJ, Ovenden JR (2014) NeEstimator V2: re-implementation of software for the estimation of contemporary effective population size $(\mathrm{Ne})$ from genetic data. Mol Ecol Resour 14:209-214

Earl DA, vonHoldt BM (2012) STRUCTURE HARVESTER: a website and program for visualizing STRUCTURE output and implementing the Evanno method. Conserv Genet Resour 4(2):359-361

Evanno G, Regnaut S, Goudet J (2005) Detecting the number of clusters of individuals using the software STRUCTURE: a simulation study. Mol Ecol 14:2611-2620

Frusetta PC (1991) Quicksilver Country: California's New Idra Mining District

Germano DJ, Rathbun GB, Saslaw LR, Cypher BL, Cypher EA, Vredenberg L (2011) The San Joaquin Desert of California: ecologically misunderstood and overlooked. Nat Areas J 31:138-147

Guedj B, Guillot G (2011) Estimating the location and shape of hybrid zones. Mol Ecol Resour 11:1119-1123

Hill WG (1981) Estimation of effective population size from data on linkage disequilibrium. Genet Res 38(3):209-216

Hurt A, Smith DA (2009) Conservation dogs. In: Canine ergonomics: the science of working dogs. CRC Press, Boca Raton, pp 175-194

Jakobsson M, Rosenberg NA (2007) CLUMPP: a cluster matching and permutation program for dealing with label switching and multimodality in analysis of population structure. Bioinformatics 23(14):1801-1806

Jones OR, Wang J (2010) COLONY: a program for parentage and sibship inference from multilocus genotype data. Mol Ecol Resour 10(3):551-555

Jost $\mathrm{L}$ (2008) $\mathrm{G}_{\mathrm{ST}}$ and its relatives do not measure differentiation. Mol Ecol 17:4015-4026

Koopman ME, Cypher BL, Scrivner JH (2000) Dispersal patterns of San Joaquin kit foxes (Vulpes macrotis mutica). J Mammal 81:213-222

Lortie CJ, Filazzola A, Kelsey R, Hart AK, Butterfield HS (2018) Better late than never: a synthesis of strategic land retirement and restoration in California. Ecosphere 9(8):e02367. https://doi. org/10.1002/ecs 2.2367

MacKay P, Smith DA, Long RA, Parker M (2008) Scat detection dogs. In: Long RA, MacKay P, Zielinski WJ, Ray JC (eds) Noninvasive survey methods for carnivores. Island Press, Washington, pp 183-222

Marsden CD, Woodroffe R, Mills MGL, McNutt JW, Creel S, Groom R, Emmanuel M, Cleaveland S, Kat P, Rasmussen GS, Ginsberg J, Lines R, André J-M, Begg C, Wayne RK, Mable BK (2012) Spatial and temporal patterns of neutral and adaptive genetic variation in the endangered African wild dog (Lycaon pictus). Mol Ecol 21:1379-1393

Marucco F, Pletscher DH, Boitani L, Schwartz MK, Pilgrim KL, Lebreton J (2009) Wolf survival and population trend using noninvasive capture-recapture techniques in the Western Alps. J Appl Ecol 46:1003-1010

Meirmans PG, Hedrick PW (2011) Assessing population structure: $F_{S T}$ and related measures. Mol Ecol Resour 11:5-18

Miller CR, Joyce P, Waits LP (2005) A new method for estimating the size of small populations from genetic mark-recapture data. Mol Ecol 14:1991-2005

Mills LS, Citta JJ, Lair KP, Schwartz MK, Tallmon DA (2000) Estimating animal abundance and noninvasive DNA sampling: promise and pitfalls. Ecol Appl 10:359-362
Nelson JL, Cypher BL, Bjurlin CD, Creel S (2007) Effects of habitat on competition between kit foxes and coyotes. J Wildl Manag 71(5):1467-1475

Nielsen R, Tarpy DR, Reeve HK (2003) Estimating effective paternity number in social insects and the effective number of alleles in a population. Mol Ecol 12:3157-3164

Ortega J, Franco R, Adams BA, Rails K, Maldonado JE (2004) A reliable, non-invasive method for sex determination in the endangered San Joaquin kit fox (Vulpes macrotis mutica) and other canids. Conserv Genet 5:715-718

Otten MR, Cypher BL (1998) Variation in annual estimates of effective population size for San Joaquin kit foxes. In: Animal Conservation forum, vol 1, no 3. Cambridge University Press, pp 179-184

Panasci M, Ballard WB, Breck S, Rodriguez D, Densmore LD, Wester DB, Baker RJ (2011) Evaluation of fecal DNA preservation techniques and effects of sample age and diet on genotyping success. J Wildl Manag 75:1616-1624

Park SDE (2001) Trypanotolerance in West African cattle and the population genetic effects of selection. University of Dublin, Dublin

Phillips S (2013) Measuring site-specific protection required to meet delisting criteria for endangered upland species of the San Joaquin Valley of California. Endangered Species Recovery Program, California State University, Stanislaus, 2 April 2013. http://esrp.csustan.edu/publications/pdf/blm_sjvrt_rpsitereco very.pdf

Piggott MP (2004) Effect of sample age and season of collection on the reliability of microsatellite genotyping of faecal DNA. Wildl Res 31:485-493

Pritchard JK, Stephens M, Donnelly P (2000) Inference of population structure using multilocus genotype data. Genetics 155:945-959

Queller DC, Goodnight KF (1989) Estimating relatedness using genetic markers. Evolution 43:258-275

Ralls K, Eberhardt LL (1997) Assessment of abundance of San Joaquin kit fox by spotlight surveys. J Mammal 78:65-73

Ralls K, White PJ (1995) Predation on San Joaquin kit foxes by larger canids. J Mammalogy 76(3):723-729

Ralls K, Smith DA (2004) Latrine use by San Joaquin kit foxes (Vulpes macrotis mutica) and coyotes (Canis latrans). West $\mathrm{N}$ Am Nat 64:544-547

Ralls K, Sharma S, Smith DA, Bremner-Harrison S, Cypher BL, Maldonado JE (2010) Changes in Kit Fox defecation patterns during the reproductive season: Implications for noninvasive surveys. J Wildl Manag 74:1457-1462

Raymond M, Rousset F (1995) An exact test for population differentiation. Evolution 49:1280-1283

Richmond JQ, Wood DA, Westphal MF, Vandergast AG, Leaché AD, Saslaw LR, Butterfield HS, Fisher RN (2017) Persistence of historical population structure in an endangered species despite near-complete biome conversion in California's San Joaquin Desert. Mol Ecol 26:3618-3635

Ruell EW, Crooks KR (2007) Evaluation of noninvasive genetic sampling methods for felid and canid populations. J Wildl Manag 71:1690-1694

Santini A, Lucchini V, Fabbri E, Randi E (2007) Ageing and environmental factors affect PCR success in wolf (Canis lupus) excremental DNA samples. Mol Ecol Notes 7:955-961

Schoon GA (1996) Scent identification lineups by dogs (Canis familiaris): experimental design and forensic application. Appl Anim Behav Sci 49(3):257-267

Slatkin M (1995) A measure of population subdivision based on microsatellite allele frequencies. Genetics 139:457-462

Smith DA, Ralls K, Hurt A, Adams B, Parker M, Davenport B, Smith MC, Maldonado JE (2003) Detection and accuracy rates of dogs trained to find scats of San Joaquin kit foxes (Vulpes macrotis mutica). Anim Conserv 6:339-346 
Smith DA, Ralls K, Cypher BL, Maldonado JE (2005) Assessment of scat-detection dog surveys to determine kit fox distribution. Wildl Soc Bull 33:897-904

Smith DA, Ralls K, Hurt A, Adams B, Parker M, Maldonado JE (2006) Assessing reliability of microsatellite genotypes from kit fox faecal samples using genetic and GIS analyses. Mol Ecol 15:387-406

Solberg KH, Bellemain E, Drageset OM, Taberlet P, Swenson JE (2006) An evaluation of field and non-invasive genetic methods to estimate brown bear (Ursus arctos) population size. Biol Conserv 128(2):158-168

Spiegel LK, Tom J (1996) Studies of the San Joaquin kit fox in undeveloped and oil-developed areas. California Energy Commission, Sacramento

Spiering PA, Gunther MS, Wildt DE, Somers MJ, Maldonado JE (2009) Sampling error in non-invasive genetic analyses of an endangered social carnivore. Conserv Genet 10(6):2005

Standley WC, Berry WH, O'Farrell TP, Kato TT (1992) Mortality of the San Joaquin kit fox (Vulpes velox macrotis) at Camp Roberts Army National Guard Training Site, California. National Technical Information Service, Springfield, United States Department of Energy Topical Report EGG 10617-2157, pp 1-12

Stansbury CR, Ausband DE, Zager P, Mack CM, Miller CR, Pennell MW, Waits LP (2014) A long-term population monitoring approach for a wide-ranging carnivore: Noninvasive genetic sampling of gray wolf rendezvous sites in Idaho, USA. J Wildl Manag 78:1040-1049

Statham MJ, Bean WT, Alexander N, Westphal MF, Sacks BN (2018) Historical population size change and differentiation of relict populations of the endangered giant kangaroo rat. J Hered (in review)

Stenglein JL, Waits LP, Ausband DE, Zager P, Mack CM (2010) Efficient, noninvasive genetic sampling for monitoring reintroduced wolves. J Wildl Manage 74:1050-1058

Taberlet P, Griffin S, Goossens B, Questiau S, Manceau V, Escaravage N, Waits LP, Bouvet J (1996) Reliable genotyping of samples with very low DNA quantities using PCR. Nucleic Acids Res 24:3189-3194

Taberlet P, Luikart G, Waits LP (1999) Noninvasive genetic sampling: look before you leap. Trends Ecol Evol 14:323-327

U.S. Fish and Wildlife Service (1967) Native fish and wildlife. Endangered species

U.S. Fish and Wildlife Service (1998) Recovery plan for upland species of the San Joaquin Valley, California. Region 1. U.S. Fish and Wildlife Service, Portland

U.S. Fish and Wildlife Service (2010) San Joaquin kit fox 5-year review: summary and evaluation. U.S. Fish and Wildlife Service, Sacremento
vanOosterhout C, Hutchinson WF, Wills DPM, Shipley P (2004) MICRO-CHECKER: software for identifying and correcting genotyping errors in microsatellite data. Mol Ecol Notes 4:535-538

Waits L, Paetkau D (2005) Noninvasive genetic sampling tools for wildlife biologists: a review of applications and recommendations for accurate data collection. J Wildl Manag 69:1419-1433

Waits LP, Luikart G, Taberlet P (2001) Estimating the probability of identity among genotypes in natural populations: cautions and guidelines. Mol Ecol 10:249-256

Wang J (2016) A comparison of single-sample estimators of effective population sizes from genetic marker data. Mol Ecol 25(19):4692-4711

Wang J, Santure AW (2009) Parentage and sibship inference from multilocus genotype data under polygamy. Genetics 181:1579-1594

Waples RS (2006) A bias correction for estimates of effective population size based on linkage disequilibrium at unlinked gene loci. Conserv Genet 7(2):167

Waples RS, Anderson EC (2017) Purging putative siblings from population genetic data sets: a cautionary view. Mol Ecol 26:1211-1224

Waples RS, Do CH (2008) LDNE: a program for estimating effective population size from data on linkage disequilibrium. Mol Ecol Resour 8(4):753-756

Waples RS, Do CH (2010) Linkage disequilibrium estimates of contemporary $\mathrm{Ne}$ using highly variable genetic markers: a largely untapped resource for applied conservation and evolution. Evol Appl 3(3):244-262

Waples RS, Yokota M (2007) Temporal estimates of effective population size in species with overlapping generations. Genetics 175(1):219-233

Waples RS, Luikart G, Faulkner JR, Tallmon DA (2013) Simple life history traits explain key effective population size ratios across diverse taxa. Proc R Soc Lond Ser B 280:20131339

White PJ, Ralls K (1993) Reproduction and spacing patterns of kit foxes relative to changing prey availability. J Wildl Manag 57:861-867

Wilbert TR, Woollett (Smith) DA, Whitelaw A, Dart J, Hoyt JR, Galen S, Ralls K, Meade DE, Maldonado JE (2015) Non-invasive baseline genetic monitoring of the endangered San Joaquin kit fox on a photovoltaic solar facility. Endanger Species Res 27:31-41

Williams DF, Germano DJ (1992) Recovery of endangered kangaroo rats in the San Joaquin Valley, California. Trans West Sect Wildl Soc 28:93-106

Woollett (Smith) DA, Hurt A, Richards N (2014) The current and future roles of free-ranging detection dogs in conservation efforts. In: Gompper ME (ed) Free-ranging dogs and wildlife conservation. Oxford University Press, Oxford 